\section{P121 PROSPECTIVE COMPARISON OF CHARCOAL SWABS VERSUS NEAR-PATIENT DIRECT CULTURE PLATE INOCULATION FOR THE CULTURE OF GONORRHOEA IN HIGH-RISK PATIENTS}

${ }^{1}$ Annabelle Harrison, ${ }^{1}$ Hannah Cheney-Lowe, ${ }^{2} J o h n$ McSorley*, ${ }^{2}$ Siobhan Murphy, ${ }^{2}$ Gary Brook. 'Imperial College Medical School, London, UK; ${ }^{2}$ Central Middlesex Hospital, London, UK

\subsection{6/sextrans-2016-052718.175}

Background/introduction Gonorrhoea culture is required to monitor antibiotic resistance and is recommended for all patients known or suspected to be infected. In July 2015 our laboratory service requested us to switch from near-patient direct plating of high-risk swabs to sending charcoal swabs urgently to the lab.

Aim(s)/objectives To compare the efficacy of direct plating versus charcoal swabs for GC culture.

Methods Between July and November 2015 all patients who had a positive GC NAAT or where otherwise at high risk and had not received antibiotics had two culture swab specimens taken from the infected site: 1 . a charcoal swab sent urgently to the laboratory for plating there and 2. a plastic loop specimen which was directly plated onto VCAT GC selective agar.

Results 61 patients had both specimen types taken. 41/61 (67\%) directly plated specimens and 31/61 (51\%) specimens transported on charcoal swabs were culture +ve $(\mathrm{P}<0.05)$. For male urethral samples, plate versus charcoal, the results were 29/ $34(85 \%)$ vs $22 / 34(65 \%)(\mathrm{P}<0.05)$ and for endocervical specimens $7 / 14(50 \%)$ vs $6 / 14$ (43\%) (n.s.). Numbers were too small for comparison for rectal and pharyngeal swabs.

Discussion/conclusion Despite sending the charcoal swabs urgently to the laboratory, the culture-positive rate was $24 \%$ lower than for directly plated specimens. This could not be explained through order of swabbing. Near-patient direct plating of specimens has to comply with UKAS accreditation but none the less, our results showed that this was superior to charcoal swabs transported to the lab for GC culture.

\section{P122 ARE PHARYNGEAL SWABS FOR CT/GC OF VALUE IN HETEROSEXUAL MEN? A RETROSPECTIVE REVIEW OF A CLINIC COHORT}

${ }^{1}$ Maygol Dadgar, ${ }^{2} J o s e p h$ Withers Green, 'Siobhan Murphy, 'Gary Brook*. 'Central Middlesex Hospital, London, UK; ${ }^{2}$ Imperial College Medical School, London, UK

\subsection{6/sextrans-2016-052718.176}

Background/introduction Pharyngeal testing for CT/GC is generally not recommended for heterosexual men whose only sexual exposure is cunilingus. However, some clinicians in this service also started sending self-taken swabs from heterosexual men when self-taken swabs became routine practice for MSM in 2014.

Aim(s)/objectives To measure the utility of pharyngeal CT/GC swabs in heterosexual men

Methods A retrospective case-note review of all heterosexual men who had been coded as having had a pharyngeal swab for CT/GC NAAT between July 2014 and August 2015.

Results 1374 eligible patients were identified. 25/1374 (1.8\%) of these were GC NAAT + ve of which 4/25 (16\%) were +ve in the pharynx, the others being +ve in the urine. 3/4 pharyngeal +ve specimens were GC NAAT + ve in the pharynx only, 1 was positive in the urine also. 110/1374 (8\%) patients were CT
NAAT + ve of which $1 / 110(0.9 \%)$ was in the pharynx only, the rest being from urine specimens

Discussion/conclusion Out of 1374 pharyngeal swabs sent, only $5(0.4 \%)$ were CT or GC +ve, of which 1 was also +ve in the urine. The 3 lone +ve pharyngeal GC NAAT specimens could be false-positive e.g. due to a cross-reaction with non-pathogenic Neisseria sp. Similarly the single CT+ve may be a false +ve assay. Alternatively, some of those patients with a +ve test may be MSM who had not revealed their status. Whatever the explanation, the very low pick-up rate does not justify taking pharyngeal CT/GC swabs in men who identify as being exclusively heterosexual.

\section{P123 DRUG AND ALCOHOL USE IN GU MEDICINE ATTENDEES - WHAT IS THE IMPACT ON SEXUAL HEALTH?}

${ }^{1}$ Iona Maxwell*, 'Jennifer Akerman, ${ }^{2}$ Raj Patel, ${ }^{2}$ Elizabeth Foley. ${ }^{1}$ The University of Southampton, Southampton, Hampshire, UK; ${ }^{2}$ Solent NHS Trust, Southampton, Hampshire, UK

\subsection{6/sextrans-2016-052718.177}

Background/Introduction Patients attending sexual health services report higher rates of drug and alcohol use. This may lead them to ignore safer sex messages putting them at greater risk of STIs. 'Chemsex' has been recognised as an additional risk factor in MSMs, but it is unclear how widespread this is in heterosexual individuals or outside large conurbations.

Aims/Objectives This service evaluation aimed to assess the extent of the alcohol and drug use in all patients attending a GU clinic and its impact on sexual behaviour.

Methods Self-completed detailed questionnaires were incorporated into the clinic dataset for 600 consecutive patients during February 2016. Data was anonymised and analysed using SPSS v23.

Results Results show $70 \%$ of women and $75 \%$ of men reported alcohol use in the last month, however fewer than $1 / 3$ reported drug use. Men were more likely to have taken recreational drugs $(37 \% \mathrm{v} 25 \%)$. Fewer women than men reported engaging in chemsex ( $2 \%$ v $5 \%$ respectively). $25 \%$ of women and $30 \%$ of men regretted sex they had had in the last year with men more likely to attribute this to alcohol. Women reported alcohol use contributing to worse partner choice but better sex, with the converse for men. There was no association between drug and alcohol use and STI rates.

Discussion/conclusion Alcohol does not appear to impact as much upon sexual behaviour as previously suggested. Chemsex is prevalent amongst heterosexuals as well as MSMs and questions on this should be incorporated into standard data collection in clinic.

\section{P124 CONFIDENTIALITY IN SEXUAL HEALTH CLINICS: A SERVICE EVALUATION OF PATIENTS' UNDERSTANDINGS AND ATTITUDES TO ADDITIONAL CONFIDENTIALITY PROTECTIONS}

${ }^{1}$ Qiang Lu*, ${ }^{2}$ Emily Clarke, ${ }^{1,3}$ Raj Patel, ${ }^{1}$ Harriet Eatwell, ${ }^{1}$ Rohilla Maarij. ${ }^{1}$ School of Medicine, University of Southampton, Southampton, UK; ${ }^{2}$ Department of Sexual Health, Solent NHS Trust, St Mary's Community Health Campus, Portsmouth, UK; ${ }^{3}$ Department of Sexual Health, Solent NHS Trust, Royal South Hants Hospital, Southampton, UK

10.1136/sextrans-2016-052718.178 